\title{
FEATURE
}

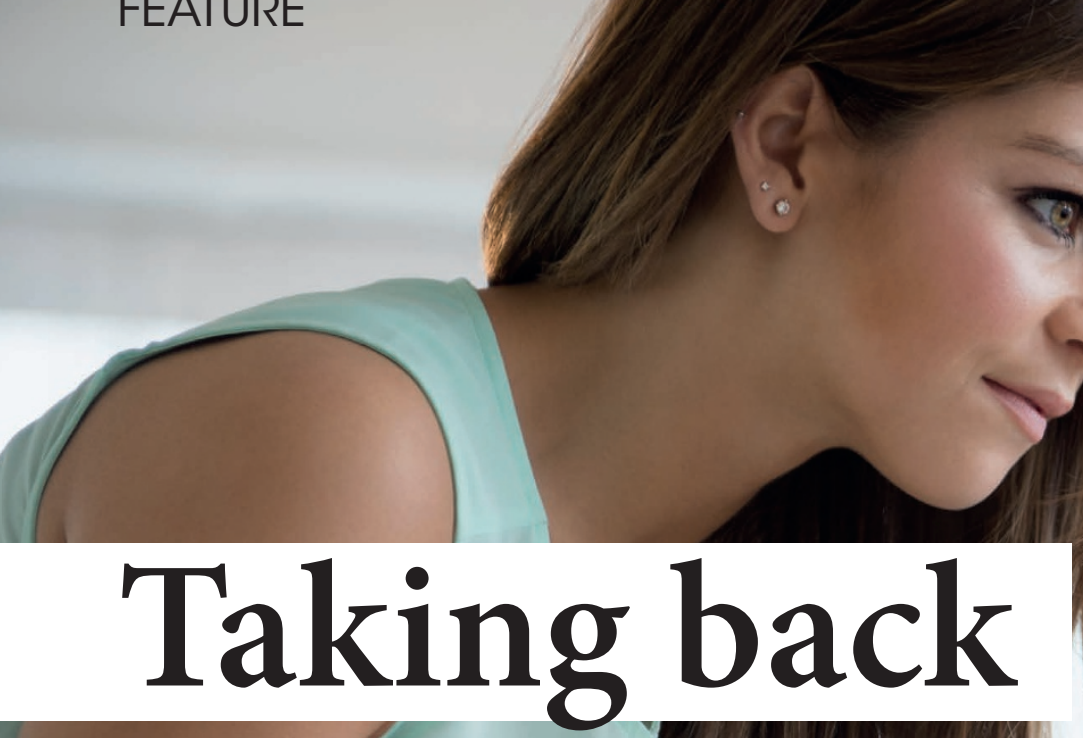

\section{control of what}

you eat
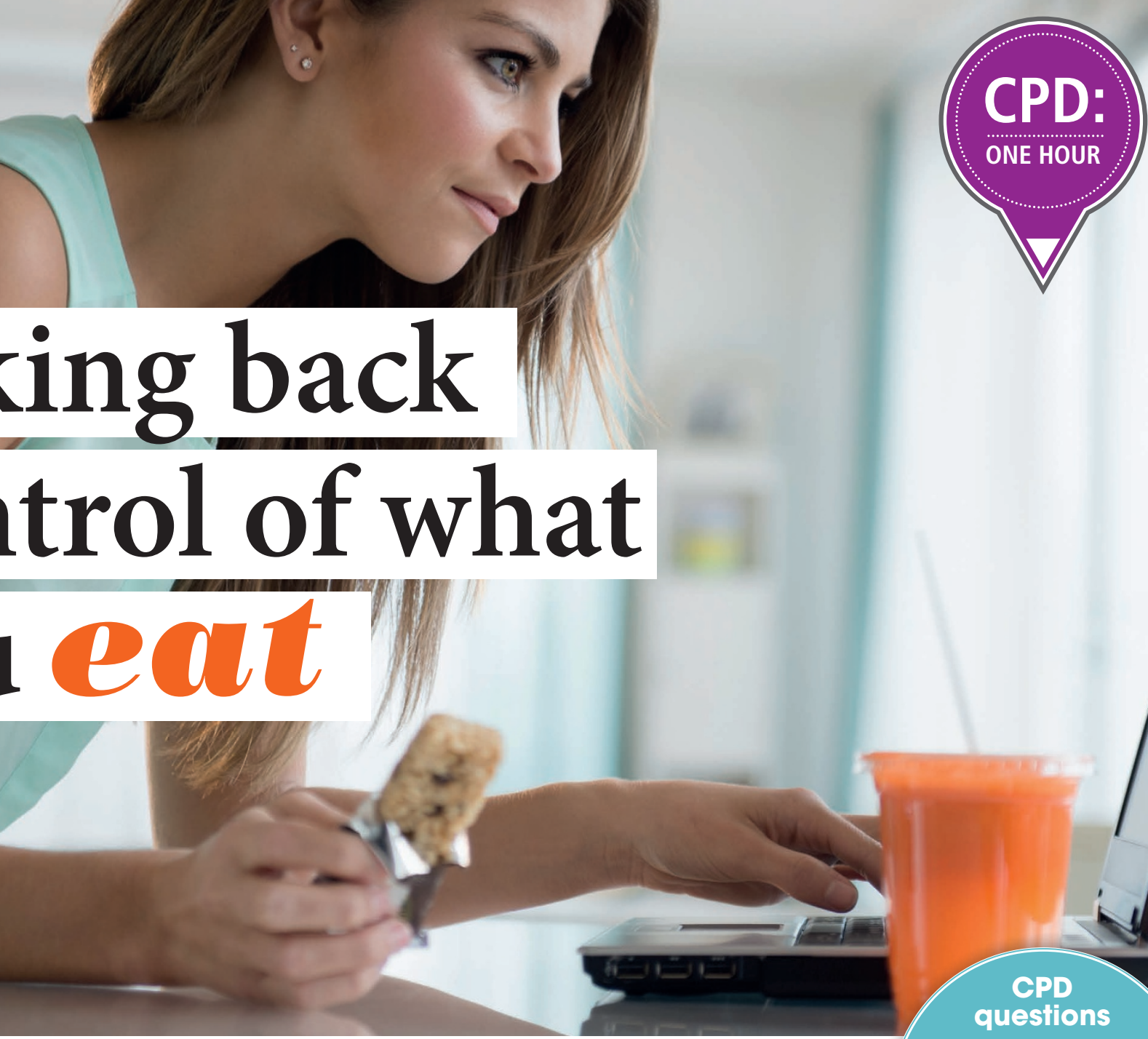
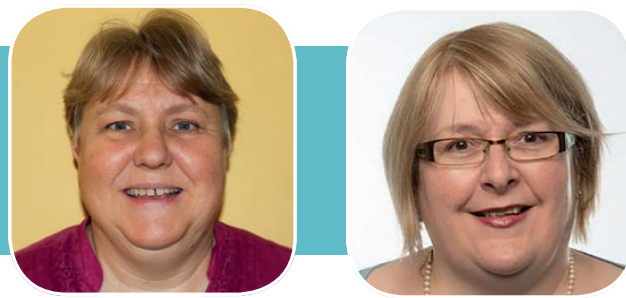

Breakfast bars, yoghurts and cook-in sauces come under the scrutiny of Cardiff-based Dr Ruth Fairchild and Maria Morgan

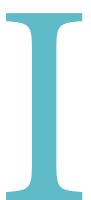

$t$ is apparent that dental team members can forget the wider approach to diet, focusing on the head and forgetting the rest of the body. On the other hand dietitians and nutritionists can often ignore

Dr R M FAIRCHILD BSc (Hons), PhD, RNutr. Cardiff Metropolitan University, Department of Healthcare and Food, Cardiff CF5 2YB

M Z MORGAN BSC (Hons), PGCE, MPH, MPhil, FFPH. Applied Clinical Research and Public Health, College of Biomedical and Life Sciences, Cardiff University, School of Dentistry, Heath Park, Cardiff CF14 4XY the impact of diet on oral health. ${ }^{1}$ This is problematic when all health professionals need to make every contact count (MECC), and thus give consistent messages to their patients. Remember that the head is part of the rest of the body - everything you eat and drink starts in the mouth, and then affects your oral and general health as it progresses through the body!

Public health is the science and art of preventing disease, promoting health and improving the quality of life through the organised efforts of society, thus dental public health is the same concept but focuses primarily on oral health. The "science and art" relates to the fact that public health draws on the skills and expertise of a wide range of disciplines, from the arts and the sciences, to deliver its goals. ${ }^{2}$ This further emphasises that members of the dental team need to work closely with partners such as dietitians and health workers and vice versa, to tackle the wider determinants of health. ${ }^{3}$

Sugar intakes, obesity and dental caries are inextricably linked. Consuming excess free sugar in food and drink is detrimental, increasing the risk of obesity, which is associated with greater risks of developing type 2 diabetes, hypertension, coronary artery disease and various cancers. ${ }^{4}$ It is believed that 1 in 20 cancers in the UK is linked to being overweight, and this is associated with 13 types of cancer, including breast, kidney, liver, colorectal and pancreatic cancer. ${ }^{5}$ Obesity is also a wellestablished risk factor for tooth decay. ${ }^{4}$

The UK presently suffers from unacceptably high levels of both tooth decay and obesity. 
Approximately one third of children aged 5 and 12 years 6 and a third of dentate adults in the $\mathrm{UK}^{7}$ have experience of dental caries. In addition, obesity in the UK has increased by $92 \%$ since the 1990s. The UK is the most obese country in Western Europe with $26.9 \%$ of the UK population classified as obese in $2015^{8}$. Excess calorie consumption can occur from eating too much of any food. However, the availability and low cost of high sugar, high calorie foods and beverages is giving particular case for concern..$^{9,10}$

In this article, we draw on the knowledge of both oral health and nutrition, to provide practical and realistic tips for the dental team, when advising patients to improve health and help Make Every Contact Count(MECC). By focusing on two of the main sugar contributors in the UK diet, breakfast bars and yoghurts, plus a hidden and often unexpected source, readymade cook-in sauces.

\section{Present day sugar \\ recommendations:}

Recent recommendations for carbohydrates ${ }^{10}$ and the 2016 updated Eatwell Guide ${ }^{11}$ both advised significant reductions in free sugar intakes for the UK population. The carbohydrate recommendations halved from no more than $10 \%$ to $5 \%$ of total energy intake; the maximum daily amount differs depending on age. In addition, the Eatwell Guide relocated high fat sugar salt (HFSS) foods outside of the plate confirming the need to eat these less often

\section{Figure 1: UK National diet recommendations}
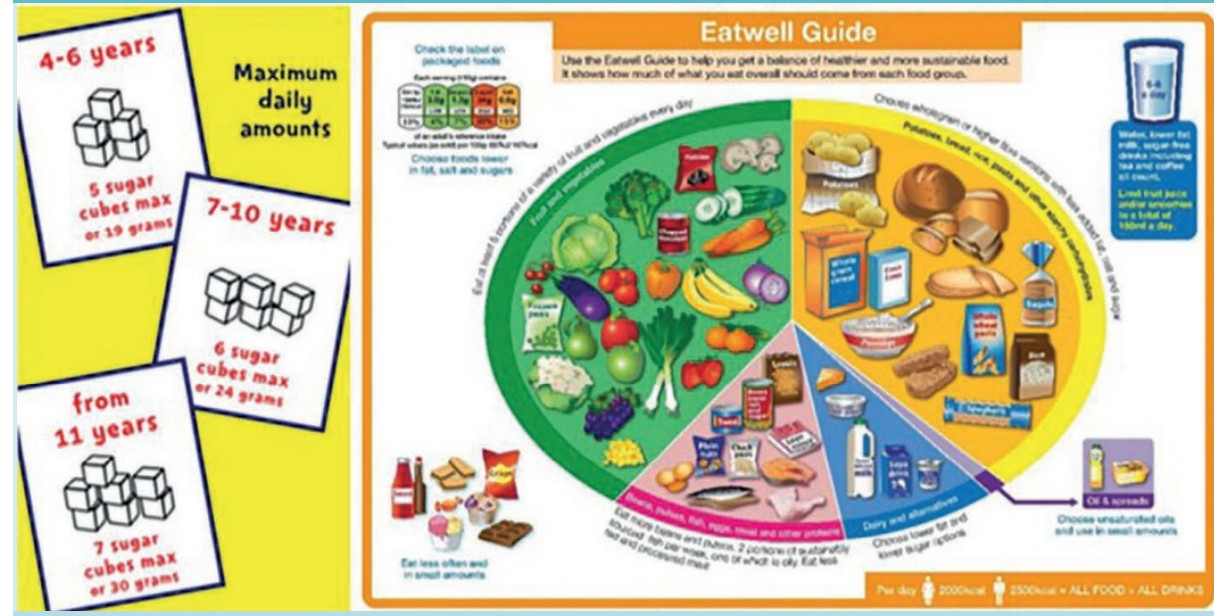

Source: NHS Change4Life, 2018 and Public Health England, 2016. https://www.nhs.uk/change4life

and in smaller portions (Figure 1). ${ }^{11}$

Bearing in mind the maximum allowance for children aged 11+ and adults of all ages is $30 \mathrm{~g}$ per day free sugars (or 7 sugar cubes) eating a badly chosen portion from any of these food product categories could provide this maximum in one hit (Tables 1-3). However, better choices are available reducing the sugar impact on your daily intake.

\section{Other tips for patients:}

If your patients reveal a love of take away food start with an easy recipe first. This homemade sweet and sour sauce costs just 21p per portion, includes only $6.6 \mathrm{~g}$ sugar (including that derived from $50 \mathrm{~g}$ of fruit and vegetables) and is ready in seconds. Make double, using a whole small tin of pineapple and freeze the spare for next time. Internet search low sugar "Sweet and Sour" recipe UK and there is usually a good recipe (substitute for instance "tomato pasta sauce" etc. for other recipes). Some of our favourite sites are the NHS live-well and BBC good food sites:

nttps://www.nhs.uk/live-well/eat-well/ how-does-sugar-in-our-diet-affect-ourhealth/?tabname=recipes-and-tips

- https://www.bbcgoodfood.com/recipes/ collection/low-sugar

Table 1: Sweet n sour sauces: hidden sugar*

\begin{tabular}{|c|c|c|c|}
\hline Product & $\begin{array}{l}\mathrm{g} \text { of } \\
\text { sugar per } \\
\text { portion }\end{array}$ & Tsp (4g) per portion & Price per portion $(p)$ \\
\hline Takeaway sweet n sour sauce & 31 & & 180 \\
\hline Sharwood's & 19.6 & & 45 \\
\hline Uncle Bens & 18.2 & & 43 \\
\hline Uncle Ben's extra Pineapple & 15.5 & & 43 \\
\hline Sainsbury's basics & 13.1 & & 14 \\
\hline Sainsbury's extra pineapple & 12.1 & & 16 \\
\hline Sainsbury's lighter & 11.8 & & 16 \\
\hline Homemade** & 6.6 & & 21 \\
\hline Uncle Bens no added sugar & 2.2 & & 43 \\
\hline
\end{tabular}




\begin{tabular}{|c|c|c|c|}
\hline Product & $\begin{array}{l}\mathrm{g} \text { of sugar per } \\
\text { portion }\end{array}$ & Tsp (4g) per portion & Price per portion $(p)$ \\
\hline Asda split pot (150g) & 24 & & 35 \\
\hline Muller corner (150g) & 23.4 & & 68 \\
\hline $\begin{array}{l}\text { Muller corner strawberry } \\
\text { shortcake }(135 \mathrm{~g})\end{array}$ & 23.1 & & 68 \\
\hline $\begin{array}{l}\text { Nestle strawberry with mini } \\
\text { smarties (120g) }\end{array}$ & 22.6 & & 37.5 \\
\hline Onken fat free (150g) & 20 & & 47 \\
\hline Koko non-dairy (125g) & 15.5 & & 60 \\
\hline Activia (125g) & 13.6 & & 38 \\
\hline Asda Low fat (112g) & 13.5 & & 22 \\
\hline Muller light (175g) & 12.4 & & 68 \\
\hline Alpro (150g) & 12.3 & & 100 \\
\hline $\begin{array}{l}\text { Homemade }{ }^{* *} 1 \text { pot natural } \\
\text { yoghurt, } 28 \mathrm{~g} \text { strawberries and } 1 \\
\text { tsp reduced sugar jam }\end{array}$ & $\begin{array}{l}11 \mathrm{~g} \\
(6.2 \mathrm{y}, 1.7 \mathrm{~s}, 3 \mathrm{j})\end{array}$ & & 60 \\
\hline Frubes (70g) & 9.4 & & 25 \\
\hline $\begin{array}{l}\text { Homemade** } 1 \text { pot natural } \\
\text { yoghurt, } 28 \mathrm{~g} \text { strawberries }\end{array}$ & $\begin{array}{l}8 \mathrm{~g} \\
(6.2 \mathrm{y}, 1.7 \mathrm{~s})\end{array}$ & & 60 \\
\hline
\end{tabular}

\section{Yogurts}

People become acclimatised to a high sugar diet; ${ }^{12}$ don't be afraid to start where your patient is at. Switching from a commercial high sugar yoghurt to a natural yoghurt with fresh fruit may be too sudden a change, so wean them off with a half natural yoghurt half fruited commercial variety, then switch to the homemade, fresh fruit and low sugar jam, before finally switching again to the lowest sugar option. Natural yoghurt contains no sugar other than lactose naturally present in the milk, which means the added sugar only comes from the fruit (or other sweetening agents) you add. You are in control.

\section{Cereal bars}

Eating on the go especially if hungry always leads to poor food choices, a little bit of planning goes a long way in sugar reduction; nutrient density and gives you a better portion size which will keep you full for longer. However, you need to bear in mind the added sugar content of the huge range of breakfast cereals available to a UK consumer. Shredded wheat, Weetabix, Cornflakes, Rice Crispies and Shreddies are lower sugar choices, whilst the majority of breakfast cereals marketed specifically to children contain over $30 \%$ sugar. $^{13}$

Portion size is also important when calculating sugar intakes. The manufacturer's recommended portion may not be that

Figure 2: Cereal portion as advised on back of pack nutrition label

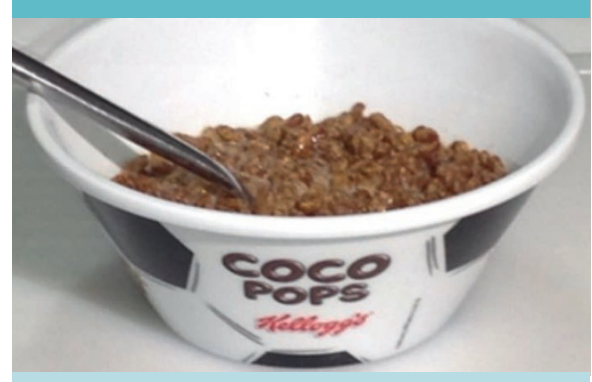

Reproduced from Khehra R, Fairchild R M, Morgan M Z, Br Dent J, 2018, 225: 164-169, with permission from Springer Nature. displayed on the packet, or the amount you require to fill you up. This can have significant consequences when a portion recommended by the manufacturer on the nutrition label (Figure 2 ) provides $170 \mathrm{kcals}$ and $11 \mathrm{~g}$ free sugars whilst the portion depicted on the pack (Figure 3) provides $510 \mathrm{kcals}$ and $34 \mathrm{~g}$ free sugars. ${ }^{13}$ Do you need to use a smaller bowl?

\section{Figure 3: Cereal portion image as depicted on cereal packet}

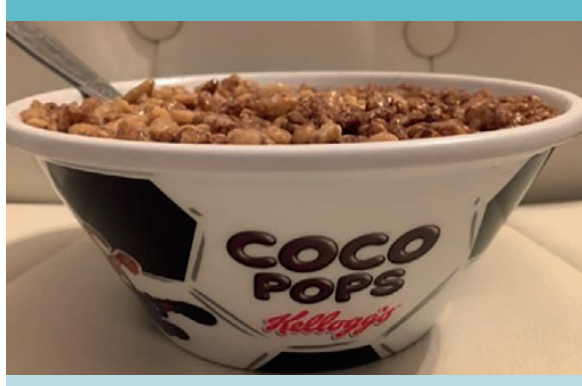

Reproduced from Khehra R, Fairchild R M, Morgan M Z, Br Dent J, 2018, 225: 164-169, with permission from Springer Nature. 
Table 3: Cereal bars... make time for breakfast.... it makes sense from a sugar perspective and saves money!

\begin{tabular}{|c|c|c|c|}
\hline Product & $\begin{array}{l}\text { g of } \\
\text { sugar } \\
\text { per } \\
\text { portion }\end{array}$ & Tsp (4g) per portion & $\begin{array}{l}\text { Price per } \\
\text { portion }(p)\end{array}$ \\
\hline Nakd berry delight $(35 \mathrm{~g})$ & 16.6 & & 62 \\
\hline $\begin{array}{l}\text { Belvita berry breakfast \& yoghurt crunch ( } 2 \\
\text { biscuit } 51 \mathrm{~g} \text { ) }\end{array}$ & 13 & & 56 \\
\hline Tesco strawberry fruity bake (37g) & 12.91 & & \\
\hline Go ahead strawberry yoghurt bar (2 slices, 36g) & 12.6 & & 40 \\
\hline $\begin{array}{l}\text { Special } \mathrm{K} \text { red berries cereal with semi skimmed } \\
\text { milk }(30 \mathrm{~g})\end{array}$ & 11 & & 35 \\
\hline Alpen strawberry with yoghurt bar (29g) & 10 & & 40 \\
\hline $\begin{array}{l}\text { Tesco wheat biscuits ( } 2 \text { biscuits, } 40 \mathrm{~g}), 28 \mathrm{~g} \\
\text { strawberries with } 125 \mathrm{ml} \text { skimmed milk }\end{array}$ & 9.34 & & 40 \\
\hline Bounce red berry breakfast bar $(45 \mathrm{~g})$ & 8 & & 100 \\
\hline Special K juicy red berry bars (27g) & 7.6 & & 45 \\
\hline Pulsin strawberry fruity oat bar ( $25 \mathrm{~g})$ & 7.4 & & 50 \\
\hline
\end{tabular}

\section{Conclusion}

It doesn't have to be expensive to eat healthily and home cooked can be lower in sugar and calories as long as you control portion size. Is it time you take back control of what you eat? Help your patients (and yourself) make small, achievable changes that can be embedded into everyday lives. This can be achieved whether you are a MasterChef or not!

\section{References:}

1. Shah K, Hunter M.L., Fairchild R and Morgan MZ (2011) A comparison of the nutritional knowledge of dental, dietetic and nutrition students. British Dental Journal. 210, (1), 33-38.

2. Morgan M (2018) The glue that brings dentistry together. BDJ Team 5, Article number: 18210

3. Fairchild R.M and Morgan M.Z (2007) Delivering multi-disciplinary public health in action - the Cardiff food strategy case study. Public Health Nutrition. 10: 42-48.

4. British Association for the Study of Community Dentistry (2016). Position statement on recommended actions to reduce the consumption of free sugars and improve oral health. Available on request from the corresponding author.

5. National Cancer Institute. Obesity and cancer. (2017). Available at https:// www.cancer.gov/about-cancer/causesprevention/risk/obesity/obesity-fact-sheet (accessed November 2018).

6. Child Dental Health Survey Summary Report (2013) http://digital.nhs.uk/ catalogue/PUB17137 (accessed November 2018)

7. Adult Dental Health Survey Summary Report (2009) http://digital.nhs.uk/ catalogue/PUB01086 (accessed November 2018)

8. Organisation for Economic Co-operation and Development (2017) obesity update. https://www.oecd.org/els/health-systems/ Obesity-Update-2017.pdf (accessed November 2018)

9. World Health Organization (2015) Guideline: sugar intake for adults and children. http://www.who.int/mediacentre/ news/releases/2015/sugar-guideline/en/ (accessed November 2018)

10.Scientific Advisory Committee on Nutrition (2015) Carbohydrates and Health. https://www.gov.uk/government/ publications/sacn-carbohydrates-and- health-report (accessed November 2018)

11.Department of Health (2016) The Eatwell Guide https://www.gov.uk/government/ publications/the-eatwell-guide (accessed November 2018)

12. Wise PM, Natress L, Flammer LJ, Beauchamp GK (2016) Reduced dietary intake of simple sugars alters perceived sweet taste intensity but not perceived pleasantness. American Journal Clinical Nutrition 103(1):50-60. doi: 10.3945/ ajcn.115.112300.

13. Khehra R, Fairchild RM, Morgan MZ. UK children's breakfast cereals - an oral health perspective. (2018) British Dental Journal. 225(2): 164-169. doi:10.1038/ sj.bdj.2018.531

\section{CPD questions}

This article has four CPD questions attached to it which will earn you one hour of verifiable CPD. To access the free BDA CPD hub, go to https:// cpd.bda.org/login/index.php. 